\title{
Grillparzers Dramatik als Problem der zeitgenössischen österreichischen Theaterzensur
}

\section{Christian Grawe}

"Die Gerichtsbarkeit der Bühne", sagte der junge Schiller 1784 in seinem Vortrag Was kann eine gute stehende Schaubühne eigentlich wirken? vor der kurfürstlich deutschen Gesellschaft in Mannheim,

Die Gerichtsbarkeit der Bühne fängt an, wo das Gebiet der weltlichen Gerichtsbarkeit sich endigt. Wenn die Gerechtigkeit für Gold verblindet und im Solde der Laster schwelgt, wenn die Frevel der Mächtigen ihrer Ohnmacht spotten und Menschenfurcht den Arm der Obrigkeit bindet, übernimmt die Schaubühne Schwert und Waage und reißt die Laster vor einen schrecklichen Richterstuhl. [...] Hier nur hören die Großen der Welt, was sie nie oder selten hören - Wahrheit. ${ }^{1}$

Aber zu dieser Zeit hatte der junge Dramatiker selbst schon erfahren, daß die Mächtigen durchaus nicht gewillt waren, sich vor den schrecklichen Richterstuhl der Schaubühne reißen zu lassen, daß die Großen der Welt die Wahrheit gar nicht hören wollten, sondern alles taten, damit sie ihnen nicht von der Bühne entgegenschallt. Sie verhängten die Zensur und hinderten das Theater daran, Schwert und Waage zu führen. Ja, Max Martersteig behauptet in seiner Darstellung Das deutsche Theater im neunzehnten Jahrhundert rundheraus:

Die einzige triftige Theaterfrage für die Regierungen ist allezeit die Theaterzenzur. ${ }^{2}$

$\mathrm{Daß}$ dies einmal in erheblichem Maße gerade auch auf die "Klassiker" zutraf, ist für die modernen Leser und Theaterbesucher, ja manchmal selbst für die Literaturhistoriker durch den Klassikerstatus der Unantastbarkeit und den Respekt vor dem Wort der großen Dichter zum Teil verschüttet worden. Der authentische Text ist uns eine so selbstverständliche Voraussetzung des Umgangs mit ihnen geworden, daß wir uns kaum noch bewußt sind, als wie bedenklich oder gar unzumutbar sie den Zensurbehörden ihrer Zeit und ihrer unmittelbaren Nachwelt erschienen. Erst der Abstand von einigen Jahrzehnten nimmt meist einem Werk die Brisanz. Das Zeitgenössische, das die Grenzen der akzeptierten Normen überschreitet, wird immer weit stärker als störend, gefährlich oder subversiv empfunden als das in historischer Ferne Liegende, an das die Menschen sich

\footnotetext{
1. Friedrich Schiller, Sämtliche Werke. 5. Bd. München ${ }^{6} 1980$, S. 823 u. 828.

2. Leipzig ${ }^{2} 1924$, S. 274.
} 
gewöhnt haben. Zensurprozesse werden selten um die Literatur der Vergangenheit geführt. Was aber eine Zeit den Ohren und Augen der Zuschauer nicht zumuten will und womit sie geschockt werden kann, ist immer ein Schlüssel zu ihrem Selbstverständnis. Auch daher ist die Zensur, wie Karl Glossy sagt, einer "der wichtigsten Zweige der Culturgeschichte". 3

Und doch handelt es sich hier um einen zu wenig beachteten Aspekt der literarischen Wirkungsgeschichte, denn er taucht darin meist nur auf, wenn die Forschung von kritischen politischen Impulsen getrieben wird - Zensurforschung wird selten in der Absicht unternommen, die Autorität des Staates über das Individuum zu bestätigen - oder wenn die Literatur wie jüngst - so Peter Uwe Hohendahl - als "Institution" begriffen wird, die nicht als die Gesamtheit der vorgefundenen literarischen Texte und ihrer Autoren aufgefaßt, sondern "als der Ort" verstanden wird, "wo durch literarische Praktiken Autoren, Texte und Leser überhaupt erst konstituiert werden", ${ }^{4}$ so daß die Literaturwissenschaft über die Texte selbst hinaus ihr Interesse an deren Schicksal in der Öffentlichkeit entdeckt und das literarische Leben einer Zeit im weitesten Sinn als Teil ihres Forschungsgegenstandes begreift.

Da die Theaterzensur, also der Eingriff der Obrigkeit in den Aufführungstext oder die Aufführungsweise eines Stückes oder gar dessen völliges Aufführungsverbot - aber natürlich auch generell die Zensur von Buchpublikationen - in Deutschland vom 18. bis zum 20. Jahrhundert zum schriftstellerischen Alltag gehörte und das Werk mancher Dramatiker lebenslang vom Kampf gegen die Zensur geprägt war, verdient das "System Zensur" mit seinen Zensurbestimmungen, -behörden und -strafmaßnahmen und mit der Verstümmelung von literarischen Texten, aber auch den Angriffen auf die Zensur und dem Unterlaufen ihrer Autorität stärker in die literarische Forschung einbezogen $\mathrm{zu}$ werden, als das in so manchen literaturgeschichtlichen Darstellungen der Fall ist.

Wolfgang Frühwald hat kürzlich im Hinblick auf die vielen verharmlosten oder unvollständigen Klassikerausgaben vor allem des 19. Jahrhunderts "eine Zensur-Philologie" ${ }^{15}$ gefordert. So nötig sie ist, sie bildet doch nur einen Aspekt einer Literaturgeschichte der Zensur, denn diese berührt die verschiedensten Bereiche der Literaturhistorie. Sie ist etwa ein Phänomen der Literatursoziologie, sofern sie das staatliche, klerikale oder plebiszitäre Kontrollsystem, das die

3. Karl Glossy, "Zur Geschichte der Theater Wiens I (1801-1820)". Sonderdruck aus dem Jahrbuch der Grillparzer-Gesellschaft 25 (1915), S. 238.

4. Peter Uwe Hohendahl, Literarische Kultur im Zeitalter des Liberalismus 18301870. München 1985, S. 33.

5. Wolfgang Frühwald, "Erst das Feigenblatt dann den Lorbeer." In: Klassiker Magazin 4 (1990), S. 21. 
Literatur überwacht und einschränkt, in verschiedenen Zeiten und politischen Systemen und damit die Rolle der Literatur in einer Gesellschaft und den ihr gewährten Spielraum erforscht; ein Phänomen der Rezeptionsforschung, sofern sie das durch die Zensur verfälschte oder sonst beeinträchtigte Bild eines Autors oder eines Werkes in den Augen der Mit- oder Nachwelt untersucht; ein Phänomen der Dichterbiographie, sofern sie den Umgang des Autors mit der Zensur und seine eigenen Eingriffe in seine Werke thematisiert; und ein Phänomen der Literaturpsychologie, sofern sie die mentale Selbstzensur des Autors schon im Schaffensprozeß seines Werkes, also die Internalisierung der Zensurforderungen und deren Beeinflussung der Künstlerphantasie zu erfassen versucht, was naturgemäß äußerst schwierig ist, weil diese Einwirkungen sich dem rationalen Zugriff des Autors selbst meist entziehen.

Diese Vernachlässigung durch die Literaturgeschichtsschreibung gilt ganz besonders für die Theaterzensur, offenbar weil ihr Wirken historisch wesentlich ungreifbarer ist als das der Zensur von Druckprodukten. Die einschlägigen österreichischen Zensurbestimmungen im hier diskutierten Zeitraum etwa, die Zensurvorschriften vom 22. Februar 1795 und vom 14. September 1810, erwähnen die Theaterzensur nicht. Selbst die Karlsbader Beschlüsse, in Österreich weniger wichtig, weil sie hinter den tatsächlichen Zensurverhältnissen eher zurückblieben, verlieren über die Theaterzensur kein Wort. Auch die vorliegenden neueren Publikationen über die deutsche Zensur im 19. Jahrhundert ${ }^{6}$ berücksichtigen die Theaterverhältnisse gar nicht oder kaum.

Dabei wird gerade die Theaterzensur fast immer schärfer gehandhabt als die Druckzensur, und das aus gutem Grund, denn hier geht es nicht einfach um einen Text, dessen Bekanntwerden man verhindern will; hier geht es um das lebendige Spiel auf der Bühne, das gefährliche außertextliche Komponenten enthält.

Erstens gibt die Anschaulichkeit des Bühnengeschehens vor einer auf engem Raum versammelten Menschenmenge dem Text eine größere emotionale Wirkung und, durch die Vergegenwärtigung auch jeder historischen Handlung, eine größere Aktualität; zweitens ist der Text in ein Ensemble von Theaterelementen - Mimik und Gestik, Kostüm und Bühnenbild, Auftritte und Abgänge, imitierende und parodierende Anspielungen - eingebettet; und drittens hat das Publikum hier

6. Julius Marx, Die österreichische Zensur im Vormärz. München 1959 (=Österreich Archiv); Dieter Breuer, Geschichte der literarischen Zensur in Deutschland. Heidelberg 1982 (=Uni-Tb 1208); Edda Ziegler, Literarische Zensur in Deutschland 1819-1848. Materialien und Kommentare. München / Wien 1983 (=Literatur-Kommentare 18). Brauchbarer dagegen: Robert Heindl, Geschichte, Zweckmäßigkeit und rechtliche Grundlage der Theaterzensur. O.O. und o.J. [1907]. Als kleine Sammlung von Dokumenten kann dienen: Alfred Kleinberg, Die Zensur im Vormärz. Leipzig/Prag/Wien 1917 (=Aus Österreichs Vergangenheit, Nr.9). 
Gelegenheit, sich durch Ge- und Mißfallenskundgebungen oder gar Zwischenrufe in das Bühnengeschehen einzuschalten und es dem Zorn oder Gelächter preiszugeben. Da all dies sich an jedem Theaterabend verschieden gestalten kann, ist es bei der Theaterzensur auch nicht mit dem einmaligen Verbot getan. Vielmehr ist eine ständige Überwachung der Bühnen notwendiger Bestandteil jeder wirksamen Theaterzensur.

Hierin liegt auch die Crux der Forschung. Anders als bei der Druckzensur, die sich aufgrund präziser Zensuranweisungen und zensurierter Druckexemplare recht gut ermitteln läßt, ist man bei der Theaterzensur auf ein Mosaik von Informationssteinchen angewiesen, um ein angemessenes Bild der Bühnenpraxis zu gewinnen, der oft keine präzise Zensurtheorie entspricht. Bühnenwirkung läßt sich ohne die unwiderruflich verlorene Anschaulichkeit nur schwer erschließen.

Nun ist gerade das österreichische Kaiserreich in der ersten Hälfte des 19. Jahrhunderts ein lohnendes Objekt für die Zensurforschung, denn es ist außer Rußland zweifellos der europäische Staat mit dem striktesten Zensursystem. Selbst Julius Marx, der sein Buch über Die österreichische Zensur im Vormärz doch in der erklärten Absicht schreibt, "zu einer gerechteren Beurteilung der Zensur und der mit ihrer Durchführung betrauten Behörden" ${ }^{7}$ beizutragen, muß zugeben:

Jedenfalls war die österreichische Zensur die umfassendste, die man denken kann. Von der Grabinschrift bis zum Lexikon wurde alles Geschriebene oder Gedruckte, vom Manschettenknopf bis zum Kupferstich jede Abbildung geprüft. Bei Bildern auf Ringen, Busennadeln oder Pfeifenköpfen war auch das Bestreben, jedes Abzeichen geheimer Gesellschaften zu verhindern, mitbeteiligt. Bei der Musik waren Texte oder Zeichnungen zu beachten, revolutionäre oder politische Gesänge waren verpönt; manchmal beanstandete man Widmungen. ${ }^{8}$

Nicht einmal Marx' Salvierung der strengen Zensur des Burgtheaters hält Stich:

1. Marx führt diese auf das Bedürfnis zurück, die "Vornehmheit der $<$ Burg $>$ " zu wahren. Aber das Resultat der Zensurpolitik bestand gerade darin, "daß die Könige der deutschen Dichtkunst von der Hofbühne ausgeschlossen blieben und die Kärrner die Hauptstütze des Repertoires bildeten", ${ }^{9}$ die erstrebte Vornehmheit also unterwandert wurde.

2. Marx hält die Aufführung von zensurierten Stücken für entschuldbar, weil

7. Marx, a.a.O., S. 7.

8. Ebd., S. 55.

9. Karl Glossy, "Zur Geschichte der Wiener Theatercensur I." In: Jahrbuch der Grillparzer-Gesellschaft 7 (1897), S. 296. 
"man die klassischen Stücke selbst ungekürzt lesen konnte". Aber gerade das war oft nicht der Fall. Es gehörte zur Wiener Theaterpraxis, daß die aufgeführten, also verstümmelten Fassungen gedruckt wurden. Das ist der Grund, weshalb der junge Grillparzer nach Marx' eigenem Urteil während der französischen Besetzung Wiens 1809 , als die Zensur vorübergehend gelockert war, Goethes sonst unzugängliche Werke kaufte.

3. Marx behauptet, "Bei Vergleichen mit den anderen Bühnen des deutschen Sprachraums schneidet das Burgtheater keineswegs schlechter ab." ${ }^{10}$ Aber tatsächlich hatte kein deutscher Staat, nicht einmal Preußen, ein so lückenloses Kontrollsystem der Bühne wie Österreich - und vor allem Wien, denn es galt laut dem Wiener Theaterzensor Hägelin die Regel, daß in der Provinz aufgeführt werden durfte, was in Wien die Theaterzensur passiert hatte, aber nicht umgekehrt:

Der Prager Theatralzensor hat es um etliche dreißig Meilen leichter als der wienerische in Zulassung mancher Stücke von heiklerem Stoffe; wenn das dortige Gubernium keinen Anstand nimmt, so ist alles gut [...] Es gibt Stücke, die beinahe überall aufgeführt werden können, nur sind sie für Wien nicht anpassend. ${ }^{11}$

$\mathrm{Da}$ unter diesen Umständen die österreichische Theaterzensur das Objekt weitverbreiteten Spottes innerhalb und außerhalb des k.u.k. Reiches war, kann nicht verwundern. Mit Augenzwinkern oder Verachtung kolportierte man die vielen absurden oder kleinlichen Zensurentscheidungen wie Adolf Glaßbrenner, der in Berlin ja selbst nichts zu lachen hatte, 1836 in Bilder und Träume aus Wien:

In der Burg hatte ein Schauspieler zu sagen: Da möcht' ich ja lieber ein Pfaffe werden! Die Censur streicht den Pfaffen heraus und legt dafür einen "Schuft" ein. In der Leopoldstadt wurde ein Stück einstudirt, in welchem von einem Manne die Rede war, der rothe Haare hatte. Die Censur machte aus den Haaren Augenbraunen, vielleicht, weil die Haare eines hohen Beamten in's Röthliche spielten. Aus einer Rolle, in welcher in parenthesi stand: (sie lehnt sich an's Fensterkreuz) strich der Censor das Kreuz fort, und ein erotisches Lied, welches mit den Worten begann:

"Schau' ich in Deine Augen,

Seh' ich den Himmel offen",

änderte der strenge Censor, um den Himmel nicht profaniren zu lassen, dahin:

"Schau' ich in Deine Augen,

Seh' ich die Pforte offen."

10. Marx, a.a.O., S. 57 .

11. 14. Mai 1802; zit. nach Theo Modes Die Urfassung und einteiligen Bühnenbearbeitungen von Schillers "Wallenstein". Leipzig/Reichenberg/Wien 1931, S. 51. 
Dies ist Alles factisch. ${ }^{12}$

Gerade das Hoftheater genoß übrigens in vielen deutschen Staaten im Gegensatz zu Österreich das Privileg der Selbstzensur. August Wilhelm Iffland machte dies zur Bedingung seiner Anstellung, als er 1797 das königliche Schauspiel in Berlin übernahm, und schrieb am 10. Februar $1799 \mathrm{stolz}$ an Schiller:

Das Theater hat keine Zensur; ich hüte mich lieber, etwas zu tun, wodurch wir eine bekommen könnten. ${ }^{13}$

Zu fragen ist aber natürlich, ob diese Scheinhoheit des Theaters nicht gelegentlich zu einer Verschärfung der Zensur durch übertriebene Vorbeugung führt, weil der Toleranzspielraum der Zensurbehörde nicht getestet wird.

Die Berliner Tradition der Unabhängigkeit der königlichen Bühnen von der Zensur lebte noch bis nach 1848, als das Hofschauspiel dagegen kämpfte, unter das neue Zensurgesetz des Polizeipräsidenten Karl Ludwig von Hinckeldey zu fallen - vergebens.

Franz Grillparzer lebt in der Literaturgeschichte als "wohl das edelste Opfer, das die Zensur zur Strecke gebracht" ${ }^{14}$ hat.

Kein anderer deutscher Dichter (so schreibt Heinrich Hubert Houben) ist durch die polizeiliche Beaufsichtigung der Literatur, [...] so heillos verwundet worden wie er. ${ }^{15}$

Der Kommentar der neuen Grillparzer-Ausgabe des Klassiker Verlags spricht geradezu von den "Schikanen" der Zensur, denen "der Autor ausgesetzt war."16

Aber stimmt das? Wohl klagt Grillparzer immer wieder über die Zensur, wohl berichtet er anschaulich über seine absurd erscheinenden Erlebnisse mit ihr; aber ob die österreichische Zensur sich ihn als Opfer erwählte und ihn schikanierte,

12. Bilder und Träume aus Wien. Leipzig 1836, Bd. 2, S. 134.

13. Iffland an Schiller (10.2.99) Schillers Werke, Nationalausgabe, Bd. 38. I, S. 35.

14. Friedrich Walter, "Die zensurierten Klassiker. Neue Dokumente theresianischjosephischer Zensur." In: Jahrbuch der Grillparzer-Gesellschaft 29. (1930), S. 147.

15. Heinrich Hubert Houben, Verbotene Literatur von der klassischen Zeit bis zur Gegenwart. Ein kritisch-historisches Lexikon über verbotene Bücher, Zeitschriften und Theaterstücke, Schriftsteller und Verleger. 2 Bde., Berlin 1924. Artikel Grillparzer Bd. 1, S. 221-235; Zitat auf S. 221.

16. Franz Grillparzer Werke in sechs Bänden. Hrsg. von Helmut Bachmaier. Frankfurt/M. 1986ff., Bd. 2 (Dramen 1817-1828), S. 644. 
kann nur im Rahmen einer Untersuchung der seinerzeitigen österreichischen Theaterzensur beantwortet werden, deren Behörden und Grundsätze kurz vorgestellt werden sollen, bevor die Frage nach Grillparzers Behandlung durch sie wieder aufgenommen wird.

\section{II}

Auf welcher rechtlichen Grundlage und nach welchen Grundsätzen fand die Theaterzensur in Österreich von vor der französischen bis zur gescheiterten deutschen Revolution statt? Obwohl man annehmen kann, daß schon im Spätmittelalter Theateraufführungen kirchlich und staatlich überwacht wurden, war hier, da der größte Teil des Theaters bis ins 18. Jahrhundert auf höfischen oder halb-öffentlichen Bühnen wie Orden, Schulen oder Handwerkerinnungen produziert wurde, eine interne Selbstzensur meist gewährleistet. Es verstand sich von selbst, daß auf der Hofbühne des Fürsten nichts dargestellt wurde, was dessen Mißfallen erregen konnte. Dafür war der Kavalier verantwortlich, der den höfischen Lustbarkeiten vorstand. Problematisch waren eigentlich nur die wandernden Schauspieltruppen, deren Repertoire auf das Volksvergnügen ausgerichtet war und die die Hanswurst-Komödie kultivierten, bei der derbe Scherze, häufig durch stummes Spiel ausgedrückt, und gewagtes Extemporieren an der Ordnung waren. Aber um die Mitte des 18. Jahrhunderts änderte sich im Rahmen der Aufklärung die Rolle des Theaters. Jetzt soll es nicht mehr der fürstlichen Prachtentfaltung und Unterhaltung oder der Volksbelustigung dienen, sondern der Hebung des kulturellen Niveaus, der "Erziehung des Menschengeschlechts". Die Bühne wird zum Vehikel nationaler Bildung, zur "moralischen Anstalt" erklärt. Sie soll nicht bloße Ergötzung, sondern "eine Schule der Sitten und des Geschmacks seyn". ${ }^{17}$ Nun beginnt in Deutschland die Ära der Gründungen fester Theater, und mit ihnen entsteht ein anspruchsvoller Spielplan. Nicht zufällig werden 1770 in Österreich kurz nacheinander mit Joseph von Sonnenfels und Franz Carl Hägelin, von dem Friedrich Walter sagt, daß er "mit bedauerlichem Eifer seinem Amte oblag", ${ }^{18}$ als "Theatralcensoren" Männer eingesetzt, die sich vor allem um die Hebung der Schulbildung Verdienste erworben hatten, denn beides, Theater und Schule, ist Teil des aufklärerischen Bildungsprogramms Josephs II. Die Theaterzensur wird zum pädagogischen Instrument. Sie soll die Würde des Theaters wahren, indem sie moralische Entgleisungen und sexuelle Derbheiten unterbindet. Das

17. Aus Franz K. Hägelins Denkschrift zur Theaterzensur von 1795, die vollständig abgedruckt ist in: Glossy, "Theatercensur." S. 238-340; Zitat auf S. 299. Künftig im Text zitiert als Hägelin mit Seitenzahl.

18.

Walter, a.a.O., S. 145. 
unkontrollierbare Extemporieren, Markenzeichen der Spaßmacherfiguren, wird deshalb bis in die achtziger Jahre zum Hauptangriffsziel der Theaterreformer und der Theaterzensoren und in Österreich 1770 durch den Kaiser aufgrund eines Promemoria von Sonnenfels verboten.

Hier waren im Extemporieren nach dieser Denkschrift des neuen Theaterzensors sogar auch "Anreden [...] Kleidungsarten und Attribute [...] hauptsächlich aber Geberden, durch welche oft eine an sich unschuldige Rede zur größten Zote werden kann"19 einbegriffen. Daß eine solche Form der Theaterzensur sinnvoll sei, wurde im absoluten Staat auch von den Intellektuellen anerkannt. Von gebildeten Zensoren ausgeübt, führte sie selten zu ernsthaften Reibungen.

Erst mit dem geistigen Zusammenbruch des Absolutismus in den Jahrzehnten vor und vor allem nach der französischen Revolution, als die Idee der Selbstbestimmung des Menschen sich durchsetzte, entwickelte sich die Zensur zum Instrument der geistigen und politischen Knebelung der nach Freiheit dürstenden Untertanen. Der ideologische Wandel, der hier stattgefunden hat, läßt sich schon an den Artikeln über die Zensur in den einschlägigen Lexika ablesen. Zedler kommt in seinem Großen vollständigen Universallexikon 1733 noch mit wenigen Zeilen aus, die kaum politische Implikationen haben:

Censor librorum, ein Aufseher, der ein Buch oder Schrifft, so gedruckt werden soll, zuvor durchlieset und approbiret, damit nichts der Religion und dem Staat nachtheiliges darinne gelassen werde. Daher heist Censur eine solche Beurtheilung und vorsichtige Durchlesung eines Buches oder Schrifft. Auf Academien hat die Censur der Decanus in jeder Facultät, und censirt ieder, was zu seiner Facultät gehöret, an andern. Orten aber pflegen auch andere solches zu verrichten. ${ }^{20}$

Dagegen enthält Krünitz' Oeconomische Encyclopaedie von 1776 schon einen über fünf Seiten langen Artikel, der gerade die politischen Implikationen der Zensur ausführlich diskutiert.

Vollends in den neunziger Jahren, als die deutschen Fürsten das Übergreifen

19. Sonnenfels' "Promemoria, Die Einrichtung der Theatral Censur betr." ist abgedruckt in: Glossy, Theatercensur, S. 258-261 (Zitat auf S. 259) und in Hilde Haider-Pregler, Des sittlichen Bürgers Abendschule. Bildungsanspruch und Bildungsauftrag des Berufstheaters im 18. Jahrhundert. Wien/München 1980, S. 345-347. Sonnenfels betont ausdrücklich, daß Zensur "nicht nur in Ansehung des Inhalts der Stücke selbsten, sondern auch in Ansehung deren Aufführungsart" und sogar der "Anschlagszettl" stattfinden solle. Vgl. zu Sonnenfels: Günter Brosche, Joseph von Sonnenfels und das Wiener Theater. Diss. Wien 1962.

20. Bd. 5, Halle/Leipzig 1733, Sp. 1817. 
der revolutionären Umwälzungen auf Deutschland befürchteten, diente die Zensur der Herrschaftssicherung und stieß dabei vorübergehend - heute würde man die Jahre 1792/93 als "Trendwende" bezeichnen - auch auf erhebliche Zustimmung in der Öffentlichkeit, der die Radikalisierung der französischen Revolution zu weit ging.

Eine strengere Zensur schien der Obrigkeit nun auch deshalb nötig, weil die immer breiter werdende Schicht des gebildeten Bürgertums ihre eigene vom höfischen Leben unabhängige städtische Kultur immer mehr durchsetzte, die sich schwerer kontrollieren ließ. Im Zusammenhang damit entstanden neben den Hoftheatern immer mehr kommerzielle Bühnen, die die Theaterszene vielfältiger und unüberschaubarer machten und die größere Wachsamkeit der Behörden herausforderten. Die Hoftheater, denen die Selbstzensur Grenzen zog, hatten gegen diese zensurale Kontrolle nichts einzuwenden, weil sie nicht daran interessiert sein konnten, daß die neue Konkurrenz größere Freiheit genoß als sie selbst. So erwies sich eine striktere Organisation und Bürokratisierung der Zensur mithilfe von Richtlinien und Verwaltungsapparat als erforderlich.

Als sich nach 1815 die Enttäuschung über die ausgebliebenen politischen Reformen breitmachte und das liberale Bürgertum immer dringlicher die Geistesfreiheit, die für die deutschen Regierungen Anathema war, als Inbegriff von Menschenwürde und Fortschrittlichkeit auffaßte und immer heftiger danach verlangte, schaukelten sich nun nach kurzfristigen Zensurerleichterungen unter dem Einfluß Napoleons der Ruf nach Freiheit des politischen und kulturellen Lebens und die Zensur gegenseitig auf, bis 1848 die Revolution die letztere vorübergehend beseitigte. Die Zensur war eine schwärende Wunde im Fleisch des Volkes geworden. Den berühmten Paragraphen 18 der Verfassung des Deutschen Bundes, nach dem "gleichförmige Verfügungen über die Preßfreiheit" in Deutschland statthaben sollten, erfüllten nur die wenigsten deutschen Staaten, und auch sie wurden ab 1819 durch die Karlsbader Beschlüsse gezwungen, das geistige Leben einzuschränken. Diese verfassungswidrig zustandegekommenen Zensurmaßnahmen und politischen Beschränkungen ("Bundes-Staatsstreich" ${ }^{21}$ ) erwähnten zwar wieder, wie erwähnt, die Theaterzensur nicht, schufen aber eine Atmosphäre des Mißtrauens, der Unterdrückung und Verfolgung, die sich auch auf die Bühne auswirkte. Nicht zufällig entstand die in Preußen bis 1848 gültige Regelung der Theaterzensur unmittelbar danach, nämlich 1820. Das Theaterpublikum reagierte auf die Säuberung der ihm vorgesetzten Texte, indem es die Szene zum Tribunal und in gezielten Beifalls- oder Mißfallenskundgebungen seine Ansichten deutlich machte. In dieser Zeit entstand der Begriff "Tendenzbeifall". Diese unliebsamen Reaktionen des Publikums erforderten nun

21. Eberhard Büssem, Die Karlsbader Beschlüsse von 1819. Die endgültige Stabilisierung der Restaurativen Politik im Deutschen Bund nach dem Wiener Kongreß von 1814/15. Hildesheim 1974, S. 298. 
systematische vorbeugende Maßnahmen. Überall an den deutschen Bühnen - etwa in Königsberg 1811, in Trier 1814, in Kassel 1821, in Köln 1823, um nur ein paar Beispiele zu nennen - entstanden daher Theaterverordnungen, die vor allem das Extemporieren und Nicht-Beachten von Zensurstrichen auf Seiten der Darsteller und lautstarke Äußerungen auf Seiten der Zuschauer strikt verboten. Durch starke Theaterwachen wurde das Publikum zudem in Schach gehalten. Ludwig Börne berichtet im ersten seiner Briefe aus Paris von einem Theaterbesuch im September 1830:

Die Theaterwache in Darmstadt war gewiß funfzig Mann stark. Ich glaube auf je zwei Zuschauer war ein Soldat gerechnet. ${ }^{22}$

Aber durch all diese Maßnahmen wurde das Ohr des Publikums nur geschärft für jede leiseste Anspielung, die zu höhnischem Lachen oder zu Beifall Anlaß geben konnte; und wie nicht anders zu erwarten, war diese Sucht, Beziehungen zu aktuellen Zuständen herzustellen oder Zweideutigkeiten in den expurgierten Texten zu finden, dort am ausgeprägtesten, wo die Zensur am umfassendsten war: in Österreich. Carl Ludwig Costenoble, der als Schauspieler von Altona nach Wien gekommen war, fand "die Phantasie der Hoftheatermenschen weit verderbter [...] als die des frivolsten Hamburgers" 23 und berichtet, daß man am Burgtheater Stücke vom Spielplan absetzte, weil das Publikum sie auf lebende Personen bezog. Vor allem, wenn es um die kaiserliche Familie ging, war äußerste Vorsicht geboten:

Zum Namenstage der Kaiserin zum erstenmale: Der alte Junggeselle unter dem Titel Die Hausgenossen, und dazu zum erstenmale Trau, Schau, Wem? unter dem Titel Wie man sich täuscht. Die Direktion nahm Anstand, die Titel: Alter Junggeselle und Trau, Schau, Wem? beizubehalten. Der alte Junggeselle, fürchtet man, könne auf Vater Franz und Trau, Schau, Wem? auf die Kaiserin böslich bezogen werden. ${ }^{24}$

Ob also "die natürliche Malitz der Menschen", wie Hägelin behauptet, "allzeit mehr geneigt sey, das Böse aus den Vorstellungen herauszuziehen als das Gute" 25 oder ob nicht vielmehr eine rigorose Theaterzensur das Theaterpublikum gerade dazu erzieht, ist die Frage.

22. 1. Theil. Hamburg 1832, S. 3.

23. Carl Ludwig Costenoble, Aus dem Burgtheater 1818-1837. Tagebuchblätter. 2 Bde. Wien 1889, Bd. 1, S. 20.

24.

Ebd., Bd. 1, S. 25 f.

25. Zitat nach Glossy, Theaterzensur, S. 337. 
In der ersten Hälfte des 19. Jahrhunderts konnten drei staatliche Instanzen mit der Theaterzensur befaßt sein, die manchmal - z.B. in Österreich - diese Funktion auch nebeneinander ausübten.

Die oberste Zensurinstanz war der souveräne Fürst, der ohne Begründung zensurale Machtworte sprechen konnte und das auch tat. Gegen seine Wünsche gab es keine Einspruchsmöglichkeit. Wie weit die Willkür des Souveräns auch bei einzelnen Aufführungen gehen konnte, geht etwa aus einem Korrespondenzbericht in der Zeitung für die elegante Welt vom 22.5.1802 hervor:

Theater in Stuttgart

(20. April)

Schillers Maria Stuart wurde hier zwei Mal gegeben. Der Zulauf war ungewöhnlich. Bei der zweiten Aufführung mußte mit Marias Abgang der Vorhang fallen, weil Lesters Auftritt den Herzog zu sehr erschütterte. (S.487f.)

Der österreichische Kaiser Franz II. griff ebenfalls immer wieder in Zensurentscheidungen ein, wobei er geschickt den Ruf kultivierte, milder zu urteilen als seine Zensurbehörden, was alles in allem wohl nicht stimmt. Gelegentlich gelang es zwar durch den Appell an ihn, einzelne Stücke für die Wiener Bühne zu retten, aber andererseits bestand er öfter auch auf einer Verschärfung der Theaterzensur und lie $B$ zu nachsichtige Zensoren verwarnen. Die Zensoren wußten offenbar, was der Kaiser von ihnen erwartete; jedenfalls ließ ihn der Polizeipräsident von 1813-15, Freiherr von Hager, wissen, "daß die Zensoren lieber streng als mild seien, weil sie dadurch weniger Anstoß befürchteten". ${ }^{26}$ $\mathrm{Da}$ letzten Endes das ganze beinahe von Verfolgungswahn bestimmte Polizei-, Spitzel- und Zensurwesen im Österreich dieser Zeit vom Kaiser gestützt wurde und mit seiner paranoiden Persönlichkeit zu tun hatte, unterliegt keinem Zweifel.

Die zweite Zensurinstanz waren die Ministerien. Hier konkurrierten die Staatskanzlei und das Innen-, Kultus- und Außenministerium, die zum Teil verschiedene Interessen hatten.

In Österreich waren sie alle an der Durchführung der Zensur, auch der Theaterzensur beteiligt, denn ihr Urteil wurde in kritischen Fällen entsprechend ihren Fachkompetenzen eingeholt. Das Recht, das jeweilige Ministerium auszuwählen, stand dem Präsidenten der Polizei- und Zensurhofstelle zu. Die erhaltenen, von Glossy in Auswahl veröffentlichten Korrespondenzen zwischen

26. V. Bibl, Die Wiener Polizei. Wien 1927, S. 291; zit. nach Marx, a.a.O., S. 26. 
den Behörden bilden eine anschauliche Quelle für die österreichische Zensurpraxis in der ersten Hälfte des 19. Jahrhunderts. Liest man diese Stellungnahmen, dann ist man überrascht, wie intensiv und bis in welche Details sich die höchsten Beamten der Monarchie einschließlich dem Staatskanzler Fürst Metternich, dessen Staatskanzlei eine eigene Zensurabteilung unterhielt, mit der Zensur beschäftigten. Die prekäre politische Balance zwischen den Behörden schuf eine Verantwortungsscheu der unteren Chargen, die die Verwaltung umständlich und verwirrend, aber die langen Bearbeitungszeiten bei der Zensur verständlich machte.

Die Metternichsche Staatskanzlei, von deren Zensor, Hofrat Baron von Bretfeld-Chlumczansky man behauptete, er sei zu dieser Aufgabe gekommen, weil "seine Unfähigkeit dort den geringsten Schaden anzurichten vermöge", ${ }^{27}$ făllte selten ein milderes Urteil als die Zensurbehörde, sondem bestätigte oder verschärfte vorgeschlagene Zensurmaßnahmen meist, wobei häufig der Kanzler auf Anregung seines engsten Mitarbeiters, des Hofrats Friedrich von Gentz, selbst eingriff.

Gentz war der Verfasser der maßgeblichen Zensurvorschrift von 1810 , die die Klassiker zwischen den "gelehrten Werken" und den "Broschüren, Jugend- und Volksschriften, Unterhaltungsbücher[n]" einordnete. Während die ersteren "durch neue Entdeckungen, durch eine bündige und lichtvolle Darstellung, durch die Auffindung neuer Ansichten u.s.w. sich auszeichnen" und "mit der größten Nachsicht behandelt, und ohne äußerst wichtige Gründe nicht verbothen werden" sollen, müssen letztere "nach der ganzen Strenge der bestehenden Censurgesetze behandelt werden". Die Klassiker sind zwar einerseits nicht so bedenklich, können aber andererseits auch den gelehrten Werken nicht zugerechnet werden, weil "sie das wahre Wohl der Einzelnen oder des Ganzen zu befördern nicht geeignet sind." 28

Es verdient, festgehalten zu werden, daß Friedrich von Gentz, der in Wien jede Geistesfreiheit ersticken half, zu dieser Einstellung nach einer Thomas-Becketartigen Wandlung kam, denn in einem verehrungsvollen Brief an Schiller aus Berlin beklagt er sich am 31.1.1802 bitter über die "Menge schmählicher Verstümmelungen" bei der dortigen Erstaufführung von Die Jungfrau von Orleans am 23. November 1801, die Iffland "theils selbst angeordnet, theils zugelassen hat":

Ich mag Ihnen nicht sagen, wie sie von dieser Seite dem Stück mitgespielt haben. Die Rolle des Erzbischofs ist ganz gestrichen; die schönsten Szenen sind auf die Hälfte reduzirt; zuweilen mit einer Willkühr, für die sich kein Grund erdenken läßt. ${ }^{29}$

27. Houben, a.a.O., S. 229.

28. Paragraph 3-7 der Zensurvorschrift vom 14.9.1810. Zit. nach Marx, a.a.O., S. 74.

29. Schillers Werke, Nationalausgabe, Bd. 39 I, S. 161. 
Gentz behauptet trotzdem, vor Ergriffenheit von der ersten Szene "bis zum Ende des vierten Aktes ohne Unterlaß geweint ${ }^{\prime 30} \mathrm{zu}$ haben.

Bei der Tagung des Schriftstellerverbandes der DDR am 7. Juni 1979, auf der neun Mitglieder der Berliner Sektion ausgeschlossen wurden, verglich Stefan Heym die österreichische Zensur des 19. Jahrhunderts vorteilhaft mit den unerträglichen Zensurverhältnissen in seinem eigenen Land:

Die Zensurbehörde des Fürsten Metternich wurde wenigstens von dem Schriftsteller Gentz geleitet, einem geistreichen und gescheiten Mann. ${ }^{31}$

Es muß schon ziemlich schlimm um das geistige Leben eines Staates stehen, wenn Gentz als erträglicher Zensor erscheint!

Die dritte - nicht ihrem Rang, aber ihrer Funktion nach eigentlich die erste Zensurinstanz war die Zensurbehörde. Der erste der beiden entscheidenden Schritte in der staatlichen Organisation des österreichischen Zensurwesens am Ausgang des 18. Jahrhunderts bestand in der Attachierung der Zensoren an neu geschaffene, zentrale staatliche Zensurämter. Bis dahin galt, daß die Zensur von dazu beauftragten, oft pro zensierter Zeile bezahlten Fachleuten, häufig von Universitätsprofessoren ausgeübt wurde, daß es also Zensoren und Zensurinstruktionen, aber keinen zentralen zensuralen staatlichen Verwaltungsapparat gab. Um diesen einzurichten, mußte die Zensurbefugnis den wissenschaftlichen oder kirchlichen Fachinstitutionen entzogen werden, denen die Zensoren angehörten. In Österreich geschah diese Maßnahme, die den wachsenden Anteil politisch-staatlicher Probleme bei der Zensur spiegelt, 1770, als Maria Theresia Gerhard van Swieten die Leitung einer Zensur-Hofkommission übertrug, deren Rolle Joseph II. nach der Übernahme der Alleinherrschaft 1780 noch stärkte, als er "die bisherigen Zensurkommissionen in den Ländern"32 aufhob. Aber nun vollzog sich nach der französischen Revolution ein zweiter organisatorischer Schritt, durch den eine vierte, im ganzen 19. Jahrhundert dann entscheidende staatliche Instanz zur mächtigsten Zensurbehörde wurde: die Polizei.

Wie in den ersten Jahrzehnten des Jahrhunderts durch den Schock der französischen Revolution, den größeren Freiheitsanspruch des Bürgertums und das Wachsen der Städte und die damit zusammenhängenden Probleme die Polizei strikter organisiert und vergrößert und die politische Polizei eingeführt wurde, ${ }^{33}$

30. Ebd., S. 160.

31. Zit. nach Der Spiegel 44 (1990), Nr. 51 (17. 12. 1990) S. 119.

32. Zensur-Gesetz vom 11. Brachmonat 1781; zit. nach A. Wiesner Denkwürdigkeiten der Oestereichischen Zensur vom Zeitalter der Reformazion bis auf die Gegenwart. Stuttgart 1847, S. 145. 
so eroberte sie nun auch immer mehr Kompetenzen zur Aufrechterhaltung der öffentlichen Ordnung, unter anderem auch die Theaterzensur. In Österreich ging die Zensur 1801 an die 1793 geschaffene Polizeihofstelle über, die nun Polizei- und Zensurhofstelle hieB und faktisch ein eigenes Polizeiministerium darstellte, das bekanntlich von 1815 bis 1848 Graf Joseph von Sedlnitzky unterstand, der neben Metternich als Inkarnation der Reaktion galt. 1819 vollendete die Polizei ihre Zensurkompetenz, als sie dem Wiener Zentral-Bücherrevisionsamt das Recht entwand, "kleine Schriften ad usus privatos allein zu rezensieren". ${ }^{34} 35$ Aus der

33. Vgl. dazu allgemein: Wolfram Siemann, Deutschlands Ruhe, Sicherheit und Ordnung'. Die Anfänge der politischen Polizei 1806-1866. Tübingen 1985 (=Studien und Texte zur Sozialgeschichte der Literatur, Bd. 14).

34. Nach Marx, a.a.O., S.14. Vgl. zur Polizei- und Zensurhofstelle: Anna Hedwig Benna, "Organisierung und Personalstand der Polizeihofstelle (1793-1848)." In: Mitteilungen des österreichischen Staatsarchivs 6 (1953), S. 197-239.

35. Die Entwicklung in Preußen verlief ähnlich. Die 1749 unter Friedrich dem Großen eingeführte Zensur oblag den Universitäten und Justizbehörden und ging 1808 außer der Zensur politischer Gegenstände, die in die Kompetenz des Außenministeriums fiel, an die Kultusabteilung des Innenministeriums über. Ihr Leiter, Wilhelm von Humboldt, wurde mit der Einrichtung der Zensurstelle beauftragt und entwarf eine Verordnung die Zensurbehörden betreffend, die seinem politischen Mut und seiner liberalen Gesinnung alle Ehre macht, denn er konnte "sich der Frage nicht enthalten"

ob es nicht vielleicht gut sein dürfte, die Censur ganz aufzuheben und nur noch die Zeitungen und politischen Schriften einer Aufsicht zu unterwerfen, wie neuerlich im Königreich Westphalen wirklich geschehen ist

und kam zu der Antwort,

An sich ist keinem Zweifel unterworfen, daß das einzig richtige Princip uneingeschränkte Censurfreiheit ist, bei welcher jeder für die von ihm verfaßten, verlegten oder gedruckten Schriften verantwortlich bleibt. Auch muß man sich diesem Grundsatz mit der Zeit immer mehr nähem.

Sein Einsatz blieb allerdings ohne Wirkung, denn schon 1809 übernahm die Polizei in Preußen die Zensurgeschäfte und behielt sie mit kurzer Unterbrechung bis 1918.

Nach der für die preußische Theaterzensur grundlegenden "Zirkularverfügung" des Innenministeriums vom 16 . März 1820 , welche bestimmte, daß

auf keinem öffentlichen Theater (die für die königliche Rechnung administrirten ausgenommen) irgendein gedrucktes od. ungedrucktes Trauer-, Schau-, Lust- od. Singspiel ohne vorläufige Erlaubnis des königl. Regierungs-Präsidii od. derjenigen Personen, welche dasselbe mit diesem Geschäfte beauftragen wird, aufgeführt

werden darf, lag die Theaterzensur also bei den regionalen Instanzen des Innenministeriums, obwohl etwa das Außenministerium die Zeitungen und Zeitschriften und das Kultusministerium die wissenschaftliche und theologische 
Sicht des Staates mußte es wohl als die geradezu ideale Lösung erscheinen, daß in Kurhessen 1818 ausgerechnet der Polizeiminister zugleich die Intendanz des Kasseler Hoftheaters übernahm. ${ }^{36}$

Die beiden schwerwiegendsten Auseinándersetzungen Grillparzers mit dem "Feuer Ofen unserer Censur"37 sind anschauliche Beispiele für das Zusammenwirken der Zensurinstanzen und die Umständlichkeit des Verfahrens in Österreich nach der französischen Revolution: die Affären um sein Gedicht Campo vaccino 1819-20 und um sein Trauerspiel König Ottokars Glück und Ende 1823-25. Die bekannten Tatsachen sollen hier nicht wiederholt werden, ${ }^{38}$ aber im vorliegenden Zusammenhang ist folgendes wichtig:

In beiden Fällen wurden alle Zensurorgane - Polizei- und Zensurhofstelle, Staatskanzlei und Kaiser - in das Verfahren eingeschaltet. In beiden Fällen griff Metternich verschärfend ein - bei Campo vaccino redigierte er selbst die Vorlage an den Kaiser, ${ }^{39}$ und bei König Ottokar wollte seine Kanzlei es nicht bei dem Verbot der Aufführung belassen, sondern forderte auch das Verbot der Buchpublikation. In beiden Fällen bewies Grillparzer "Männerstolz vor Fürstenthronen": im einen Fall schrieb er eine überlegene Eingabe an Sedlnitzky, in der er den Präsidenten auf den Unterschied zwischen Realität und Poesie aufmerksam machte, und im anderen besuchte er darüber hinaus den "sybaritischen" Friedrich von Gentz in seiner üppigen Wohnung. In beiden Fällen

Literatur überwachte.

Die eigentliche Bedeutung dieser Verfügung liegt nicht darin, daß sich durch sie die Theaterzensurpraxis wesentlich änderte, denn auch in Preußen war in den neunziger Jahren aus Furcht vor den möglichen Folgen der französischen Revolution ein strengerer Geist eingezogen - wenn auch offenbar aufgrund der solideren aufklärerischen Tradition dort zögernder. Das Signifikante der neuen Zensurregelung ist, $\mathrm{da} B$ sie nun von den Exekutivorganen des Innenministeriums, das heißt, von der Polizei ausgeübt wurde.

Vgl. Maria Sommer, "Die Einführung der Theaterzensur in Berlin." In: Kleine Schriften der Gesellschaft für Theatergeschichte 14 (Berlin 1956). Sommers grundlegende Dissertation über die Berliner Theaterzensur (Phil. Diss., Berlin 1945) ist nach telefonischer Auskunft der Autorin nicht zugänglich.

36. Vgl. Reinhard Lebe, Ein deutsches Hoftheater in der Romantik. Kassel 1964, S. 58 .

37. August von Kotzebue als Burgtheaterdramaturg an Schiller (3.11.1798); zit. nach Friedrich Schillers Werke, Nationalausgabe, Bd. 38. I, S. 3.

38. Vgl. die einschlägigen Dokumente, Berichte und Analysen in: A. Sauer, Grillparzers Gespräche und Charakteristiken seiner Persönlichkeit, 7 Bde. Wien 1904-41; Houben, a.a.O.; Norbert Fürst, Grillparzer auf der Bühne. Eine fragmentarische Geschichte. Wien und München 1958.

39. Vgl. dazu Julius Marx, "Metternichs Gutachten zu Grillparzers Gedicht <Campo vaccino>. In: Jb. d. Grillparzer-Gesellschaft. NF 2 (1942), S. 49-69. 
erreichte die Zensur das Gegenteil ihrer Absicht. Campo vaccino wurde zur Sensation:

[...] nie hat irgend eine meiner Arbeiten eine solche Verbreitung in meinem Vaterlande erhalten als dieses Gedicht, das, wenn man es unbeachtet gelassen hätte, von dem verehrungswürdigen Publikum ohne Geschmack auf der Zunge gefressen worden wäre wie Gras. ${ }^{40}$

Das Drama König Ottokar, das durch das Gerücht von seinem Verbot schon 1824 viel Neugier und Sympathie erregte, wurde zum Skandalerfolg:

Als der Tag der Aufführung kam, gab es ein Gedränge, desgleichen man im Hofburgtheater weder früher noch später erlebt hat. Leider konnte ich die Ehre dieses Zulaufs nicht bloß mir anrechnen, es war vielmehr das Gerücht, daß das Stück von der Zensur verboten gewesen sei, was dem Publikum die Aussicht auf ein allfälliges Skandal eröffnete. ${ }^{41}$

Der Kaiser billigte im ersten Fall das scharfe Urteil seines Kanzlers, im zweiten aber verwarf er auf den Rat seines Leibarztes das Verbot. Bei dieser letzten Entscheidung ist bedenkenswert, daß dies nach Houben ${ }^{42}$ der erste Fall ist, bei dem der Kaiser von sich aus die Polizei - und Zensurhofstelle um Rechtfertigung ihres Verbots nachsuchte - doch wohl ein Zeichen seines Interesses an dem dichtenden Beamten, der wegen der Campo vaccino-Affäre als unzuverlässig galt.

Auch das Angebot des Kaisers, Grillparzers Ein treuer Diener seines Herrn für seine Privatbibliothek anzukaufen und damit aus dem öffentlichen Verkehr zu ziehen, ist ja offenbar nicht ein Akt der Bösartigkeit gegen den Dichter, sondern entsprang umgekehrt dem Bedürfnis, das Stück zwar zu unterdrücken, aber seinen Verfasser zugleich so ehrenvoll und schonend wie möglich zu behandeln und ihn auch finanziell zu entschädigen. Allerdings kannte der Kaiser seinen "treuen Diener" Grillparzer schlecht, der gegen derlei diplomatische Manipulationen einen Abscheu hatte und sich nicht ködern und kaufen ließ.

Trotz der intensiven Beschäftigung der Zensur mit Grillparzer, ist dieser keineswegs ein Lieblingsfeind der Kontrollbehörden seiner Heimatstadt gewesen, und ein Blick auf die von Glossy veröffentlichten Zensurvorgänge und -schriftwechsel zwischen 1801 und $1820^{43}$ zeigt, daß in einer Vielzahl von Fällen

40. Grillparzer, Selbstbiographie. In: Sämtliche Werke. Ausgewählte Briefe, Gespräche und Berichte. Hrsg. von Peter Frank u. Karl Pörnbacher. Bd. 4, München 1960-65. S. 109; die Charakteristik Gentz' als "sybaritisch" S. 125.

41. Ebd., S. 126.

42. Houben, a.a.O., Bd.1, S. 226. 
routinemäßig mehrere Zensurinstanzen bis hinauf zum Kaiser bemüht wurden und gelegentlich sogar eine weitere staatliche Stelle eingeschaltet wurde, mit der Grillparzer nie zu tun hatte: Bei militärischen Stücken gab der Hofkriegsrat ein zensurales Urteil ab. Im Hinblick auf die Zensurproblematik der Stücke Grillparzers ist dieser keineswegs die schikanierte Ausnahme.

Was aber machte einige Stücke Grillparzers und vor allem sein patriotisches Trauerspiel König Ottokars Glück und Ende zu Unverständnis und Mißfallen des Dichters für die Theaterzensur problematisch? Zur Beantwortung dieser Frage ist ein Einblick in die inhaltlichen Aspekte der neuzeitlichen Zensur und besonders der österreichischen Theaterzensur zwischen 1789 und 1848 nötig. Diese Eingrenzung eines guten halben Jahrhunderts ist trotz seiner vielfältigen historischen Entwicklungen gerechtfertigt, weil das österreichische Zensursystem sich, von Kleinigkeiten abgesehen, nicht veränderte; es war im ersten Jahrzehnt des 19. Jahrhunderts vollendet.

\section{IV}

Zensur im neuzeitlichen Sinn ist keine ästhetische Einschränkung, sondern bezieht sich auf drei Lebensbereiche, die wechselnd als unterschiedlich leicht korrumpierbar und gefährlich eingeschätzt werden: 1. auf Religion und Kirche, 2. auf Politik und Gesellschaft und 3. auf Moral. Die einschlägigen Lexika und Zensurbestimmungen stimmen darin völlig überein. Schon Johann Georg Krünitz' Lexikon-Artikel, der die Theaterzensur nicht eigens unterscheidet, definiert 1776:

1) Müssen die Bücher, welche im Lande gedruckt werden, oder einzuführen und zu verkaufen erlaubet werden sollen, nichts gefährliches für die Religion in sich enthalten. Hierunter werden nicht die Streit-Schriften der verschiedenen Religionsverwandten, und noch weniger die symbolischen Bücher und andere Schriften der widrigen Religionsverwandten im Lande verstanden, gesetzt, daß sie auch die herrschende Religion mit harten Ausdrücken angreifen, wann diese nur nicht auf Beschimpfungen, Schmähen und Lästern hinauslaufen. Denn Bücher, welche die christliche Religion überhaupt mit Spöttereien und Lästerungen angreifen, sind allemal Bücher, welche für die Religion gefährlich sind. 2) Müssen die im Lande zu druckende oder einzuführende Bücher nichts zum offenbaren Verderb der Sitten in sich enthalten. Doch ist dieses nicht im strengen Verstande zu nehmen, denn sonst würde man die meisten Romanen, die meisten Gedichte, und viele andere Schriften, confisciren müssen. Man muß zufrieden seyn, wenn solche Schriften nur etwas nützliches in sich enthalten, und wenn ein Verfasser die Tugendlehre aus dem Plan seiner Schrift nicht ganz und gar ausgemustert hat. Nur solche Schriften sind zu confisciren, die alles nützlichen und vemünftigen

43. Karl Glossy, Theater Wiens. Aufschlußreich auch seine Sammlung: Geheimberichte aus dem Vormärz. Mit Einl. u. Anm. Hrsg. von C. Glossy. Wien 1912. 
Endzwecks beraubt sind, und die offenbar zu nichts anders geschrieben sind, als die verderbten Lüste und die Geilheit zu erregen, und welche in jungen Gemüthern ein unaussprechliches Verderben anrichten. 3) Sind diejenigen Bucher und Schriften nicht zu dulden, welche für die Ruhe des Stats nachtheilig sind, mit einem giftigen Tadel die Maßregeln der Regierung beflecken, Mißtrauen und Abneigung in den Herzen der Unterthanen erregen, schädliche Grundsätze wider die Regierungsform in sich enthalten, und die Ehrerbietung gegen die Regenten verletzen. ${ }^{44}$

Diese im wesentlichen für das 19. Jahrhundert geltenden Grundsätze werden nach der französischen Revolution lediglich in der Definition des dritten, des politischen Bereiches anders gefaßt, indem sie nun meist den vorher als Gefahr noch gar nicht avisierten revolutionären Umsturz des Staates direkt ansprechen. Die preußische Zensurordnung von 1819 etwa, die wesentliche Passagen des 1788 von dem damaligen Justizminister Johann Christoph Wöllner geschaffenen und ebenfalls diese drei Bereiche umfassenden Zensurgesetzes übernimmt, enthält nun einen neuen Abschnitt, der ausdrücklich

alle auf Erschütterung der monarchischen und in diesen Staaten bestehenden Verfassungen abzweckende Theorien; jede Verunglimpfung der mit dem Preußischen Staate in freundschaftlicher Verbindung stehenden Regierungen und der sie constituirenden Personen, ferner alles was dahin zielt, im Preußischen Staate oder den Deutschen Bundesstaaten Mißvergnügen zu erregen und gegen bestehende Verordnungen aufzureizen; alle Versuche, im Lande und außerhalb desselben Partheien oder ungesetzmäßige Verbindungen zu stiften, oder in irgend einem Lande bestehende Partheien, welche am Umsturze der Verfassung arbeiten, in einem günstigen Lichte darzustellen ${ }^{45}$

verbietet.

Die Prinzipien treffen auf die Theaterzensur ebenso zu wie auf die Bücherzensur, nur wurde jene im allgemeinen schärfer gehandhabt. Daher stellt Pierers Lexikon fest:

Der Theaterzensur

sind fast in allen Staaten, auch in solchen, wo Preßfreiheit herrscht, die aufzuführenden od. längere Zeit nicht auf dem Repertoire gewesenen Stücke vor der Aufführung vorzulegen, u. sie bestimmt, ob dieselben aufgeführt werden dürfen od. nicht. $^{46}$

44. Johann Georg Krünitz, Oeconomische Encyclopädie oder Allgemeines System der Land-, Haus- und Staats-Wirtschaft. 7. Theil. Berlin 1776, S. 155f.

45. Zit. nach Heinrich Hubert Houben, Der gefesselte Biedermeier: Literatur, Kultur, Zensur in der guten alten Zeit. Leipzig 1924, S. 141. 
Auch das maßgebliche österreichische Dokument für die Handhabung der Theaterzensur, die Denkschrift des Wiener Theaterzensors Hägelin von 1795 für die gebotene Aufführungspraxis in Prag erläutert, warum "die Theatralzensur viel strenger seyn müsse als die gewöhnliche Zensur für die bloße Lektüre der Druckschriften, wenn letztere auch in Dramen bestehen". ${ }^{47}$

Dieses ergibt sich schon aus dem verschiedenen Eindruck, den ein in lebendige Handlung bis zur Täuschung geseztes Werk in den Gemüthem der Zuschauer machen muß, als derjenige seyn kann, den ein blos am Pulte gelesenes gedrucktes Schauspiel bewirckt. - Der Eindruck des erstern ist unendlich stärcker als jener des leztern, weil das erstere Augen und Ohren beschäftigt und sogar in den Willen des Zuschauers treten soll, um die beabsichtigten Gemüthsbewegungen hervorzubringen, welches die bloße Lecture nicht leistet. Die Bücherzensur kann Lesebücher restringiren und folglich solche nur einer gewissen Gattung von Lesern gestatten, da hingegen das Schauspielhaus dem ganzen Publikum offen stehet, das aus Menschen von jeder Klasse, von jedem Stande und von jedem Alter bestehet. (S. 329)

Die Theaterzensur ist daher häufig nicht nur eine Zensur des Textes; sie zieht auch die Darstellung als die lebendige Realisierung des Textes und die mögliche Wirkung beider auf das Publikum in Betracht. Theaterkommissare, die die Vorstellungen selbst besuchen, sind daher nur eine natürliche Konsequenz einer effektiven Theaterzensur. In Österreich führte man sie 1803 zur Überwachung der Vorstadttheater ein, in denen das anzügliche Spiel zum Aufführungsstil gehörte. Diese Inspekteure waren verpflichtet,

bei den Generalproben eines jeden neuen Stückes sowie bei der ersten Aufführung und den Wiederholungen anwesend zu sein. Ihre Aufsicht hatte sich überdies auf das gesprochene Wort, auf die Mimik, auf das Kostüm, ja selbst auf die Dekorationen zu erstrecken; auch wurde ihnen aufgetragen, das Extemporieren, [...] mit aller Strenge zu verhüten. ${ }^{48}$

Wie nun sah die Umsetzung der Zensurgrundsätze in die Theaterpraxis aus? Hier kamen unweigerlich subjektive Entscheidungen, Vorlieben und Abneigungen einzelner Zensoren ins Spiel. Aber nicht nur, was verboten wurde, oblag der

46. Universal-Lexikon der Gegenwart und Vergangenheit oder Neuestes Encyclopädisches Wörterbuch der Wissenschaften, Künste und Gewerbe. Hrsg. von H. A. Pierer. 6. Bd., Altenberg ${ }^{2} 1841$, S. 300.

47. Hägelins Denkschrift wird zitiert nach Glossy, Theatercensur, S. 298-340; Zitat auf S. 301. Die Denkschrift wird fortan im laufenden Text nur mit Seitenzahl zitiert.

48. Glossy, Theater Wiens, S. 21. 
Entscheidung des einzelnen Zensors, sondern auch, was bei Änderungen an die entsprechende Stelle gesetzt wurde, denn obwohl zum Beispiel Hägelin ausdrücklich feststellt, daß die Zensur nicht dafür verantwortlich sei, "das Anstößige zu korrigieren und statt der vom Zensor verworfenen Stellen einen zulässigen Text einzuschalten oder hinein zu korrigieren", tat er es doch während seiner fast fünfunddreißigjährigen Amtszeit als Wiener Theaterzensor immer wieder, und zwar, als "bloße Wohltat für den Author und besondere Beförderung guter Absichten" (S. 320). Auf diese Weise fanden direkte Eingriffe von fremder Hand in den Wortlaut eines Stückes statt, für die der Dramatiker auch noch dankbar sein sollte.

Die Folgen waren manchmal auch ästhetisch unerfreulich. Es konnte schon vorkommen, daß,

da die Wiener Zensoren noch nicht ganz poetisch sind, mancher fünffüßige Jambus in einen Trochäus zusammenschrumpft oder in einen Alexandriner oder nach Umständen in einen noch mehrfüßigen Wiener Zensurvers sich verwandeln muß. ${ }^{49}$

Nach Grillparzer, der keineswegs ein prinzipieller Gegner der Zensur war, scheitert diese gerade an ihrer menschlichen Dimension. Seine Notizen "Über die Aufhebung der Zensur" gipfeln in dem Satz:

Es kann keine Zensur geben, weil es keine Zensoren gibt. ${ }^{50}$

$\mathrm{Daß}$ sich die Zensurinstanzen aufgrund der menschlichen Fehlbarkeit und Urteilsschwäche leicht gegenseitig die Schuld an uneinsichtigen Entscheidungen zuspielen konnten, liegt auf der Hand. Wenn Marx ${ }^{51}$ der österreichischen Zensur dieser Zeit zugute hält, daß ihr Ruf durch Klatsch und Gerüchte schlimmer war als ihr Wirken - was sich aber bezweifeln läßt -, dann muß mindestens dagegen gehalten werden, daß sie selbst daran die Hauptschuld trug. Im Burgtheater nannte man laut Costenoble die Polizei - und Zensurhofstelle die "Schreckens-, Streichund Verwerfungsstelle". 52

49. Die Münchener Tageszeitung Das Inland, Nr. 178, 1830; zit. nach Glossy, Theater Wiens, S. 20.

50. Wie Anm. 4, Bd. 3, S. 1063.

51. Marx, Zensur im Vormärz, S. 6, 30.

52. Costenoble, a.a.O., Bd. 1, S. 263. 
Hägelins Denkschrift von 1795 ist für die Beantwortung der Frage nach der Zensurpraxis das aufschlußreichste kulturgeschichtliche Dokument dieser Zeit und verdient eine Neuveröffentlichung. Der Verfasser gibt viele Beispiele aus der Dramatik seiner Zeit und geht bei der Beschreibung des Annehmbaren und Unannehmbaren bis ins kleinste Detail.

Er unterscheidet wie alle Zensursysteme der Zeit Verstöße "wider die Religion, wider die Staatsverfassung oder wider die Sitten" (S. 304) und differenziert bei ihrer Kontrolle im Drama (1) den Stoff und seine Moral und (2) die Sprache ("Dialog"). So ergeben sich sechs zum Teil in viele Unterpunkte gegliederte Zensurbereiche, denen Hägelin dann seine "Bemerkungen über die jetzigen Zeitumstände" anfügt, die das Gewicht gerade der politischen Bedenken in dieser Zeit unterstreichen. Komprimiert ergibt sich folgendes Bild:

\section{Stoff und Moral}

\subsection{Stoff und Moral: Religion}

"Ueberhaupt können die Religion und religiöse Gegenstände nie ein Stoff theatralischer Vorstellungen werden", weil sie "zu erhaben und ehrwürdig" sind (S.305). Auch alttestamentarische Stoffe dürfen nur als Geschichte, soweit "Ihre Handlungen aus natürlichen Triebfedern entsprungen sind" (S. 306), verwendet werden. Geistliche Personen und geistliche Kleidung dürfen nicht auf der Bühne erscheinen. Weder "kristliche Toleranz" (!) noch das Papsttum sind dramatisch zu behandeln.

\subsection{Stoff und Moral: Politik}

"Es können in einem monarchischen Staate keine Stücke aufgeführt werden, deren Inhalt auf die Abwürdigung der monarchischen Regierungsform abzielte oder der demokratischen oder einer andern den Vorzug vor der monarchischen einräumte." Ausgenommen sind hiervon die "Muster vaterländischer Tugenden" in der Antike, "weil sie nicht die Abhandlung über die Regierungsformen oder Zweifel über die Rechtmäßigkeit der landesfürstlichen Gewalt zum Gegenstande hatten" (S. 310). "Begebenheiten aus der Geschichte des österreichischen Erzhauses" (S. 311), die abfällige Behandlung von Regenten, die Mißhandlung oder Hinrichtung von Herrschern ("daß das gesittete Theater nie mit Blut befleckt werden darf", S. 313) sind daher ausgeschlossen.

"Stoffe oder Karacktere, wodurch ganze Nationen, besonders die freundschaftlichen, gemißhandelt oder als lasterhaft dargestellt werden, können nicht passirt werden. Nie muß der Tadel auf ganze Nationen, auf ganze Stände, 
besonders auf die vornehmeren und den obrigkeitlichen Stand überhaupt fallen; überall muß er nur auf das persönliche Laster, Untugend oder Thorheit gebracht werden" (S. 313). Auch der Militärstand soll geschont werden; Uniformen dürfen daher nie der Wirklichkeit entnommen werden.

"Schädliche Vorurtheile und die Verbannung derselben sind ein Gegenstand der Bühne; allein wenn es politische Vorurtheile gibt, deren Bekämpfung die Ruhe des Landes stöhren könnte, so können diese auf dem Theater nicht bekämpft werden." "Die Gesetzgebung eines Staates oder dessen bestehende Gesetze können überhaupt in keinem Stoff mit Tadel aufgeführt werden" (S. 315).

Selbstmorde dürfen nicht positiv dargestellt werden. "Auch kann der Widerstand gegen die obrigkeitliche Gewalt in Theatralhandlungen nie approbirt werden" (S. 315). Verboten sind ebenfalls "gräßliche, unnatürliche und schauderhafte Verbrechen" wie "Eltern- oder Kindesmord oder Laster wider die Natur" (S. 315f.).

\subsection{Stoff und Moral: Sitten}

Unsittliche Lehren und sittenlose Taten sollen nicht dargestellt werden. Männer dürfen auf der Bühne Frauen nachstellen; diese dürfen aber nicht nachgeben. Mätressen und Ehebrecherinnen gehören nicht ins Theater. "Epicureische" Grundsätze dürfen nicht verkündet werden.

\section{Sprache}

\subsection{Sprache. Religion}

Ausdrücke "biblischer, katechetischer, oder hierarchischer Herkunft" (S. 320) sind zu meiden; darunter fallen auch geistliche Ämter wie Papst, Bischof usw. "Heilig" ist durch "verklärt", "Sünde" durch "Mißethat, Verbrechen, Frevel, Fehler, Fehltritt, Jugendstreiche oder Vergehung" zu ersetzen. Flüche wie "Sackerment" und "kritische Ausrufe, als: Jesus Maria, heiliger Anton, ihr lieben Heiligen" (S. 325) sind nicht gestattet.

\subsection{Sprache: Politik}

"Regenten, Obrigkeiten, ganze Stände, besonders die höheren, und bestehende Gesetze (dürfen) durch allgemeine Ausfälle nicht angetastet, satyrisirt oder lächerlich gemacht werden." (S.325)

"Die Ausdrücke: Tyrann, Tyranney, Despotismus, Unterdrückung der Untergebenen müssen auf dem Theater so viel möglich vermieden werden." (S.326)

\subsection{Sprache: Sitten}

Schmutzige und schlüpfrige Ausdrücke werden nicht geduldet; dazu gehören 
schon "Ehebruch", "Hömer aufsetzen" usw.

\section{Bemerkungen für die jetzigen Zeitumstände}

"Wie diese beschaffen sind, ist Jedermann bekannt." Daher findet keine Erwähnung der französischen Revolution, keine Benutzung der Wörter "Freiheit" und "Gleichheit", "mit denen nicht zu schertzen ist", und "Aufklärung", keine Behandlung der Freiheit "im politischen Verstande" (S. 328) statt. Stücke über "Aufruhre, Empörungen, Conspirationen" sind ausgeschlossen. "Stücke, worinn von Bedrückung der Unterthanen durch Abgaben oder übertriebene Jagdbeschwerden, Bauernschinderey von Seite ihrer Gutsherren oder sogar der Beamten die Rede ist, oder deren Stoff ausmachen, unterliegen der nemlichen Bedencklichkeit." (S. 329)

Uneheliche Geburten, auch das Wort "Bastard", und "Ausfälle auf den alten und neuen Adel" (S. 330) dürfen nicht vorkommen.

Angesichts dieser langen Liste von Einschränkungen und Verboten versteht man Max Martersteigs betroffene Frage,

Was der dramatischen Kunst übrig geblieben ist, wenn alle Staatsinstitutionen, das Königtum, die Behörden, das Parlament, die Gesetze, Religion und Konfessionen, Anstand, sogar ganz allgemein Moral und Grundsätze der gesellschaftlichen Ordnung, die Ehe sowie endlich Vorgänge aus dem Leben Gegenwärtiger nicht berührt werden durften. Ohne Leisten, Leder, Zwecken, Pech und Draht kann man nicht gut einen Stiefel machen; ungefähr aber verbot doch dieses System so ziemlich alles, was wesentlich Stoff zum Drama ist. ${ }^{53}$

Das also ist die Grundlage für die Theaterzensur, an der von Werk zu Werk Grillparzers Dramatik gemessen wurde. Daß sie die Zensurhürden nicht unbeanstandet überwand, darf daher nicht überraschen.

Wie nach Hägelins Anweisungen zu erwarten, passierten Grillparzers antike Stücke die Zensur ohne Schwierigkeiten. Griechische und römische Sujets, von der Würde klassischer Bildung umgeben, genossen, selbst wenn sie politisch waren, was bei Grillparzer kaum der Fall ist, zensurale Vorrechte. Sappho, Das goldene Vließ 3 und Des Meeres und der Liebe Wellen waren daher leicht durch die Zensur zu schleusen. Bei dem letzteren Stück durften allerdings die priesterlichen Handlungen im ersten Akt laut Eintragung im Souflierbuch "nicht an geistliche Gebarungen erinnem", 54 da ja

53. Martersteig, a.a.O., S. 275f. 
keine Gegenstände auf das Theater gebracht werden durften, die lediglich und unmittelbar die Religion betreffen (Hägelin, S. 307).

Ein kurioser Fall von theatralischer Selbstzensur liegt bei Das goldene Vließ vor. Da die Medea von der alternden Sophie Schröder - sie war 1781 geboren gespielt wurde, die in den ersten beiden Stuicken des "dramatischen Gedichts in drei Abteilungen" den Áltersgegensatz zwischen Rolle und Darstellerin verbergen wollte, strich die Schauspielerin "selbst alle Stellen, die auf Medeas Schönheit hinweisen". 55

Wüster ging es nach den Maßstäben der Theaterzensur in Die Ahnfrau zu. Das Stück kreist um das sexuelle Vergehen einer Adligen ("In den Armen ihres Buhlen/ Überfiel sie der Gemahl", V. 488f.) und den Dolch, den daraufhin "des Ahnherrn blinde Wut/ Tauchte in der Gattin Blut" (V. 2536f.). Das "Pfand geheimer Lust" (V. 551) ist der Ahnherr der letzten, auf der Bühne agierenden Generation der Grafenfamilie, die nur der Tod vor der Blutschande bewahrt. Ein anstößiges Sujet, das in verschiedener Hinsicht den Zensurvorschriften ins Gesicht schlug. Nach ihnen durften "gräßliche, unnatürliche und schauderhafte Verbrechen" (Hägelin, S. 315) nicht aufgeführt werden und "wirckliche Blutschande, Ehebruch [...] nie den Stoff der dramatischen Handlung ausmachen" (S. 317). Zudem ist Berthas Ende, an der Schwelle zum Selbstmord, höchst problematisch, denn Selbstmorde waren nur dann bühnenfähig, "wenn sie als Folgen und Strafen des Lasters erscheinen" (S. 315). Die Faszination und das Mitleid aber, die ja gerade das unverschuldete Schicksal der letzten Borotins erregten, mußten Berthas Sterben und auch Jaromirs Tod in den Armen der schuldigen Ahnfrau unerträglich machen, besonders da es sich un eine gräfliche Familie handelte und hier auch die von der Theaterzensur geforderte Achtung vor den höheren Ständen ins Spiel kam. Nimmt man hinzu, daß verpönte "kristliche Ausrufe" (S. 325) wie "Gütiger Himmel!" (V. 2594) oder "Gott!" (V. 2574) in Grillparzers erstem Drama wiederholt vorkommen, dann hätte der Autor sich glücklich schätzen müssen, daß dieses leidenschaftliche Produkt trotz zweimaliger Beanstandung in der kaiserlichen Residenz über die Bretter gehen durfte.

In geringerem Maß und aus anderen Gründen gilt das auch von Der Traum ein Leben, das ebenfalls von der Theaterzensur eher milde behandelt wurde. Immerhin beginnt der zweite Akt mit Rustans Hymne an die Freiheit. Zwar hat das Wort keine direkten politischen Implikationen, aber Hägelin wußte wohl, daß "Freyheit und Gleichheit [...] Wörter (sind), mit denen nicht zu schertzen ist" (S. 328); sie wurden deshalb von der Zensur nahezu immer gestrichen. Aber

54. Zit. nach Susanna Jauker, Die Uraufführung der Dramen Franz Grillparzers auf dem Burgtheater. Phil. Diss. Wien 1962, S. 99.

55. Ebd., S. 45. 
schlimmer: In Grillparzers Stück befindet sich eine Stadt in Aufruhr; das Volk klagt seinen König des Mordes an. Das war Kontrabande der schlimmsten Art, da "Stücke, welche Aufruhre, Empörungen, Conspirationen wider die Regenten oder andere rechtmäßige Regierungen enthalten, diese Laster mögen am Ende gestraft werden oder nicht, derzeit nicht aufs Theater zu bringen sind" (S. 329). Daß Grillparzer mit einigen Strichen davonkam, die die Wirkung des Aufstands milderten und die physische Gegenwart des Heeres auf der Bühne reduzierten, ist nach den damaligen Maßstäben generös.

Das für die Literaturgeschichte wichtigste Kapitel der Zensur und Grillparzer betrifft dessen historisches Drama, das die vaterländische Tragödie auf der Wiener Bühne zu etablieren bemüht war und dabei auf den Widerstand der Theaterzensur stieß. Die österreichische Zensur machte es den Dramatikern nahezu unmöglich, historische und gar einheimische historische Sujets zu bearbeiten. Ein Blick auf Hägelins Denkschrift genügt, um zu erkennen, wie eng der Spielraum der Dichter war. Es gehörte zu den geschriebenen Gesetzen der Theaterzensur, daß die Geschichte des Habsburger Hauses tabu war, sofern ihre Darstellung kritische Elemente beinhaltete, und zu den ungeschriebenen, daß Vertreter des Erzhauses überhaupt nicht auf der Bühne dargestellt wurden. ${ }^{56}$ Jedes Infragestellen der bestehenden Ordnung, jede politisch-zweifelnde Aussage, jeder moralische Schatten auf einer Herrschergestalt oder seiner Familie, jede kritische Äußerung über eine Nation, jede mögliche Anspielung im historischen Gewand auf gegenwärtige Zustände, jedes Handlungselement und jeder Dialogfetzen, die die diplomatischen Beziehungen Österreichs zu tangieren schienen, waren verboten.

Man braucht nicht viel Phantasie, um zu sehen, daß König Ottokars Glück und Ende ein einziges zensurales Minenfeld war: der erste Habsburger-König als Bühnenfigur; der Böhmenkönig geschieden, neu verheiratet und politisch gescheitert, wobei Parallelen zu Napoleon, der bei der Uraufführung ja erst vier Jahre tot war, und dessen zweite Frau, die österreichische Erzherzogin Marie Luise, noch lebte, den Zeitgenossen sofort aufstießen; die Habsburger Nationen im Kampf gegeneinander; die neue Königin von Böhmen in offener Feindschaft zu ihrem Gemahl und auf skandalöse Weise mit einem Untertanen flirtend; ein

56. Was aus Rücksicht auf das regierende Kaiserhaus schon zu Strichen auf den deutschen Bühnen führte, wurde in Preußen erst am 20. April 1844 offizielle Zensurpolitik, als eine königliche Ordre Friedrich Wilhelms IV. verfügte, daß

in Zukunft theatralische Vorstellungen von Stücken, in welchen verstorbene Mitglieder Meines Königlichen Hauses die Szene betreten, nur dann Statt finden dürfen, wenn dazu Meine Erlaubniß ausdrücklich eingeholt worden ist. (Zitiert nach Lothar Schirmer, "'Friedrich der Große' als Theaterheld." In: Preußen. Versuch einer Bilanz. Katalog der Berliner Preußen-Ausstellung 1981. Bd. 4. Preußen - Dein Spree-Athen, Beiträge zur Literatur, Theater und Musik in Berlin. Hrsg. v. H. Kühn, S. 232.) 
Priester auf der Bühne, und wieder religiöse Ausrufe wie "ach Gott! ach Gott!" (V. 2913) - kein Wunder, daß das Zensurexemplar durch mehrere Instanzen wanderte.

Als endlich der Widerstand der Behörden gebrochen und der Kaiser die Aufführung mit den gehörigen Strichen erlaubte, war genau das geschehen, was in solchen Fällen üblich war und die Literaturgeschichtsschreibung als Problem beschäftigen muß: Die Zensur entleerte und entwirklichte das historische Material des Dramas radikal, indem sie es nach dem - wie Jakob Zeidler das 1898 nannte "Gesetz der idealen Ferne"57 umgestaltete. Schon Hägelin nennt in seiner Denkschrift das Verwischen historischer Genauigkeit bei militärischen und geistlichen Kostümen euphemistisch "ideal" (S. 308, 314). Im Fall von König Ottokars Glück und Ende, dessen frühes Zensurschicksal gut belegt ist, weil sowohl die einschlägigen Dokumente der Zensurinstanzen ${ }^{58}$ als auch die Zensurexemplare der Uraufführung im Burgtheater und der unmittelbar folgenden Inszenierung im Theater an der Wien erhalten sind, ${ }^{59}$ wurde das historische Hintergrundmaterial weitgehend eliminiert, Völkernamen verschwanden und die Verhältnisse und Feindschaften innerhalb des späteren Habsburgerreiches wurden möglichst nicht berührt. Sowohl die Ereignisse um die Königswahl als auch die Gestalten Rudolfs und Ottokars verloren an Profil. Daß hier österreichische Geschichte verhandelt wurde, konnten die Zuschauer nur noch mit Mühe erschließen.

$\mathrm{Da}$ dies kein Einzelfall war, sondern daß sich die Zensur "dem historischen Drama gegenüber" "besonders schroff [...] verhielt", ${ }^{60}$ ließe sich am Schicksal von Schillers drei Habsburger Dramen auf den Wiener Bühnen leicht erkennen, bei denen ebenfalls die dargestellten historischen Verhältnisse und Ereignisse möglichst verunklart und entwirklicht wurden. ${ }^{61}$

Wilhelm Tell etwa - um nur eins davon als Beispiel zu benutzen - wurde in Wien zunächst ganz verboten. Als das Schauspiel 1810 im Theater an der Wien endlich Premiere hatte, geschah das in einer Fassung, die Freiherr von Hager, Vizepräsident der Polizei- und Zensurhofstelle, der Staatskanzlei des Fürstkanzlers

57. Jakob Zeidler "Ein Zensurexemplar von Grillparzer's: König Ottokars Glück und Ende." In: Ein Wiener Stammbuch. Wien 1898, S. 287-311; Zitat auf S. 308.

58. Das Material ist am leichtesten zugänglich in Erläuterungen und Dokumente. Franz Grillparzers König Ottokars Glück und Ende. Hrsg. von Karl Pörnbacher. Stuttgart 1969, S. 64-81 (=Reclam UB 8103).

59. Vgl. dazu Jauker, a.a.O., S. 66f., Zeidler, a.a.O., passim und Carl Glossy, "Zur Geschichte des Trauerspiels: König Ottokars Glück und Ende." In: $J b . d$. Grillparzer-Gesellschaft 9 (1899), S. 213-247.

60. Glossy, Theatercensur, S. 24.

61. Vgl. dazu insgesamt Franz Hadamowsky, Schiller auf der Wiener Bühne 17831959. Wien 1959. 
Metternich zur Prüfung weitergab:

Die bekannte und rein historisch bearbeitete Handlung ist so motiviert, daß Österreich gar nicht erwähnt wird, kein Schatten auf den Kaiser fällt, sondern alles der Tyrannei des Vogts Geßler zugeschrieben wird.

Hager fährt mit dem rührenden Satz fort: "Viele der schönsten Stellen sind beibehalten" [Hervorhebung von mir, C.G.], und äußert dann Bedenken, weil in Wilhelm Tell "von einem Lande die Rede ist, das für Österreich verloren ging". Der Landvogt operiert also nun in einem luftleeren Raum; in wessen Diensten er steht, erfahren die Zuschauer nicht. Zu den "schönsten Stellen von Schiller", die man beibehalten hatte, gehörte jedenfalls nicht der gesamte fünfte Akt. Die von Schiller selbst mit der Stürmung der Bastille verglichene Zerstörung der Feste Zwing Uri und vor allem die ausführliche Diskussion des Kaisermords samt menschlich ergreifender Darstellung des reuigen Mörders - ein Bruderzwist in Habsburg! - darzustellen, war ausgeschlossen. Trotz dieser gravierenden Kürzung und Entwirklichung der Handlung ließ der Kanzler die Aufführung nur zögernd zu, weil "die neuesten Ereignisse in Tirol und die Verbindung, in welche einige Bewegungen in der angrenzenden Schweiz mit selbem gesetzt werden wollten, es notwendig machten, dermal noch sorgfältiger alles zu vermeiden, was zu gewissen peinlichen Rückerinnerungen Anlaß geben könnte." 62

Noch als das Schauspiel 1829 zum erstenmal im kaiserlichen Hoftheater zu sehen war, handelte es sich im wesentlichen um diese Fassung:

'Österreich und dessen damalige Verhältnisse werden gar nicht erwähnt', schrieb Hofrat Mosel an Grafen Czernin, 'und die demokratische Tendenz, die man dem Originale allenfalls zuschreiben könnte, verschwindet vor dem bloß ländlichen und allgemein menschlichen Interesse. ${ }^{63}$

Kein Wunder, daß die Hamburger Zeitschrift Telegraph 1839 berichtet, "auf österreichischen Bühnen sei im Tell der Vogt Geßler im vollen Recht und der Freiheitsheld nichts weiter als ein frecher Aufwiegler." ${ }^{16}$

Schiller und Grillparzer - die Vollender der historischen und damit der eigentlich neuzeitlichen Tragödie in Deutschland, beziehungsweise gut zwanzig Jahre später in Österreich. Durch sie erschließt sich die conditio humana nicht mehr aus einem überweltlich-religiösen Bezugssystem oder aus dem archetypischen Geschehen des Mythos, sondern aus der Geschichte als

62. Glossy, Theatercensur, S. 116.

63. Houben, wie Anm. 15, Artikel Schiller, Bd. 1, S. 566.

64. Ebd., S. 567. 
weltimmanentem Deutungsmedium des menschlichen Daseins, als dem Reich des Besonderen, des Disparaten und des Sich-Wandelnden mit der Fülle seiner wechselnden Geschehnisse und Gestalten, wie es Schillers Satz von der "Weltgeschichte", als dem "Weltgericht" so prägnant erfaßt. Der historische Fall, der, nach dramatischen Gesetzen sich gestaltend, in der modernen Tragödie gerade in der hier betrachteten Zeit zwischen französischer und gescheiterter deutscher Revolution den Anspruch paradigmatischer Repräsentanz erhebt, lebt aus der Verbindung und Spannung zweier Elemente: Das geschichtlich Einmalige muß als solches seine unverwechselbare historische Signatur bewahren und zugleich doch nicht als Abgestorbenes und Vergangenes, sondern als für die Welt- und Menschendeutung der gegenwärtigen Epoche Relevantes erscheinen. Nur dadurch verdient es, Stoff zur historischen Tragödie zu werden.

Geschichtliche Identifizierbarkeit und Wechselbezug von Historie und Gegenwart sind daher unabdingbare Koordinaten des Geschichtsdramas gerade bei Schiller und Grillparzer. Indem aber die österreichische Theaterzensur den historischen Stoff entwirklicht, "idealisiert" und all seiner möglichen Bezüge zur Gegenwart beraubt, zerstört sie das historische Drama als Bühnenereignis. Sie macht sich damit des Vergehens schuldig, das später in Joseph Roths Radetzkymarsch Hauptmann Trotta dazu treibt, den Kaiser persönlich um die Korrektur der legendenhaften Lesebuchgeschichte von dessen Rettung in der Schlacht von Solferino zu ersuchen. Die immer wiederholte Erklärung, "Es ist für Kinder", will er nicht anerkennen; er möchte den österreichischen Staat nicht auf Mythen gegründet sehen. Zu solcher kindlichen Verwandlung von Geschichte in Fantasiegebilde zwang die Wiener Theaterzensur vor 1848 den Dichter historischer Dramen ständig.

Eine mittelalterliche Welt etwa, die alle religiösen Konflikte und alle geistlichen Repräsentanten schlichtweg beseitigt, hört auf, eine wahre Reflexion des Historischen zu sein. Geschichtsdrama und österreichische Theaterzensur schließen sich daher wechselseitig aus. Es gab die historische Tragödie allenfalls gedruckt, nicht auf der Bühne. ${ }^{65}$ Ein Bruderzwist in Habsburg wäre vor 1848

65 Noch Heinrich Laube, Burgtheaterdirektor von 1849 bis 1867, beklagt

jene unglückselige Idee, Theaterstücke wie Staatsangelegenheiten $\mathrm{zu}$ betrachten und den Bedenklichkeiten der Diplomatie zu überantworten,

und erkennt dabei schon deutlich, welche Folgen diese Einstellung für das Verständnis des historischen Schauspiels hat.

Auf die dreißig Einzelstaaten des deutschen Vaterlandes wird dergestalt Rücksicht genommen, daß kein deutscher Gesandter irgendeine störende Empfindung im Theater haben dürfe. Dadurch wird ein Lebenselement des deutschen Theaters, die deutsche Geschichte, tief beeinträchtigt, und die natürlichsten Stoffe werden die schwierigsten. Dem jetzigen Drange nach Einheit zum Trotze werden die Helden der Nation nicht nur in Familienhelden verwandelt, sondern auch je nach diesen oder jenen empfindlichen Saiten, 
gerade um dessentwillen unaufführbar gewesen, was Hugo von Hofmannthal daran bewunderte, daß darin nämlich "das fast Unglaubliche gelungen (ist): den historischen Gehalt einer vergangenen Epoche ganz zu geben, und ihn in Gestalten zu geben."66 Aber der Zensur ging es um Grillparzer selbst keineswegs. Den Mythos der Zensurschikane des Dichters kann man zur Ruhe legen. Die Wahrheit ist schlimmer: So wie Grillparzers Dramatik wurde zwischen 1789 und 1848 die gesamte Bühnenproduktion und besonders das historische Schauspiel behandelt.

welche berührt werden, ausgeschlossen. Die Spaltung wird prinzipiell verewigt, und die Nation von ihrer Geschichte abgetrennt. Die Fürsten erwiesen Deutschland die größte Wohltat, wenn sie gegenseitig dem Theater die Geschichte freigäben und solche diplomatische Rücksicht ein für allemal vom Theater ausschlössen, [...].

Aber leider wird dies Kriterium noch immer selbst über die deutschen Grenzen ausgedehnt, und die Diplomatie verbietet dem Theater auch auswärtige Stoffe. Was in Frankreich und England und dem Nationalstolze gemäß in jedem seine Selbständigkeit fühlenden Reiche unerhört ist, das gilt bei uns noch für natürlich: auch das Ausland vor jeder, ich sage vor jeder, nicht vor irgendeiner unangenehmen Empfindung zu schützen in unserm Theater!

("Briefe über das deutsche Theater". In: Schriften über Theater. Hrsg. von der Deutschen Akademie der Künste. Berlin 1959, S. 45.)

66. H.v. Hofmannsthal, "Rede auf Grillparzer" (1922). In: Ausgewählte Werke in zwei Bänden. Frankfurt/M. 1957, Bd. 2, S. 664. 